\title{
Renoprotective Effects of PLGA Nanoparticles Loaded with Vitamin E in Wistar Rats, on Hypercaloric Diet
}

\author{
ADRIANA DINU ${ }^{1}$, BOGDANA VIRGOLICI ${ }^{1 *}$, DANIELA MIRICESCU ${ }^{1}$, \\ ALEXANDRA TOTAN ${ }^{1}$, ELVIRA GAGNIUC ${ }^{2}$, HORIA VIRGOLICI ${ }^{1}$, \\ DACIANA COSTINA STEFAN ${ }^{1}$, MARIA GREABU ${ }^{1}$, MARIA MOHORA ${ }^{1}$ \\ ${ }^{1}$ Carol Davila University of Medicine and Pharmacy, 8 Eroilor Sanitari Str., 050474, Bucharest, Romania \\ ${ }^{2}$ University of Agronomic Sciences and Veterinary Medicine, 59 Marasti Blvd., 011464, Bucharest, Romania
}

\begin{abstract}
Obesity is associated with renal lipomatosis, inflammation and oxidative stress. Vitamin E is a liposoluble antioxidant vitamin and PLGA (polylactic-CO-glycolic acid) nanoparticles (NPs) represent a delivery carrier of this vitamin to the abdominal viscera. The aim of this study is to evaluate the renal and systemic effects of PLGA-NPs loaded with vitamin E in high fat diet Wistar rats. Young heathy Wistar male rats (3months old, $n=20)$ were fed for 4 weeks either with standard diet or with high caloric/fat diet. These two experimental groups were divided in two subgroups and for the following 21 days, one group received PLGA-NPs loaded with vitamin E (1 mg/kg) body and the other didn't. Metabolic serum parameters, oxidative stress markers ( malondialdehyde, MDA and total thiols) from kidney homogenates were measured by spectrophotometric methods. Hematoxylineosin stain histopathologic examination of kidneys was performed. The obesogenic diet increased the serum levels for triglycerides $(p<0.001)$ and renal function markers: urea $(p<0.02)$, creatinine $(p<0.02)$ and cystatin $(p<0.01)$. The treatment reduced the kidney inflammation, prevented tubulonephrosis damage and improved the renal oxidative stress markers $(p<0.05)$ in the high fat diet group. In conclusion, PLGA-NPs loaded with vitamin $E$ had renoprotective effect in high fat diet Wistar rats.
\end{abstract}

Keywords: vitamin E, fat diet, nanoparticles, oxidative stress

\section{Introduction}

Obesity is a public burden by direct lifetime costs with reduced life expectancy and indirect costs among full time employers [1]. Diabetes mellitus, atherosclerosis and high blood pressure are comorbidities of obesity. The chronic kidney disease has high incidence in the diabetic patients and in the high blood pressure ones. So, there is an indirect link between obesity and the chronic kidney disease. Also, obesity may lead to chronic kidney disease via direct mechanisms: glomerular hyperfiltration, inflammatory milieu, dysfunction of the renin-angiotensin- aldosterone system, high transforming growth factor beta TGF- $\beta$ level, oxidative stress and the imbalance of adipocytokines production -high leptine/low adiponectine [2].

PLGA is a biodegradable polymer with promising results in the medical treatments. PLGA-NPs represents a drug delivery system which assures high bioavailability, controlled release of the drug and minimal risk toxicity. In the human body, the polymer PLGA is hydrolysed to glycolic acid and lactic acid which are non-toxic biodegradable metabolites, being approved by US Food and Drug Administration [3,4]. In rats, the biodistribution of poly(lactic-co-glycolic) acid (PLGA) nanoparticles (NP) showed higher concentrations of these small particles in the liver, kidney and spleen and they are non toxic [5]. Based on the strong antioxidant function, the reduced toxicity, the rare side effects and the low cost, vitamin E supplementation has gained the interest of the scientific communities for the development of new therapies against acute renal dysfunction [6]. It has been demonstrated that Vitamin E improves kidney function and decreases the risk of renal artery stenosis [7]. Experimental data showed that long term high fat diet induce an inflammatory microenvironment in the kidneys

*email: hvirgolici@yahoo.com 
associated with glomerulosclerosis and tubular damage [8]. Vitamin E, in high doses, $1000 \mathrm{mg} / \mathrm{kg}$ given by oral gavaje to male Sprague-Dawley rats with streptozotocin diabetes mellitus, ameliorated proteinuria ,attenuated renal tubular epithelial cell injury and interstitial fibrosis [9]. Also, oral vitamin E supplementation in young rats submitted to exhaustive exercise stress improved the kidney antioxidant defence [10].

Knowing the anti-inflammatory and the antioxidant effects of Vitamin E, the administration of this vitamin should prevent the high fat diet renal injury. In this study we used PLGA-NPs delivery system for vitamin E. The most important advantages of this delivery system in comparison to oral drug vitamin $\mathrm{E}$ administration are: good penetration into the cells, increased vitamin $\mathrm{E}$ release and improved stability of the antioxidant [5].

The aim of this study was to evaluate the renal and systemic effects of Vitamin E loaded PLGANPs $(1 \mathrm{mg} / \mathrm{kg}$ body) in Wistar rats who received high fat diet. By hematoxylin-eosin stain histopathologic examination of the kidney we could investigate the intrarenal inflammatory infiltrate. By measuring the renal malondialdehyde, a lipid peroxidation marker, and total renal thiols as antioxidants, we could analyse the oxidative stress tissue balance.

\section{Materials and methods}

Young Wistar male rats (3months old, $\mathrm{n}=10)$ were fed with a high caloric/high fat diet $(5.15 \mathrm{kcal} / \mathrm{g})$ for 4 weeks and then, for the following 21 days, they continued this diet without or with vitamin $\mathrm{E}$ loaded PLGA-NPs (1 mg/kg body) and two groups were formed: group O (obese) and group ON (obese treated), respectively. In parallel, other 10 young Wistar male rats were raised and kept on a standard diet $(3.5 \mathrm{kcal} / \mathrm{g})$, but half of them received vitamin E loaded NPs $(1 \mathrm{mg} / \mathrm{kg}$ body) in the last 21 days and group S (standard) and group SN (standard treated) were constituted. The treatment was given by oral gavage.

The rats had access to standard rodent chow and water ad libitum. Food intake was measured daily. They were housed in cages at $20-22^{\circ} \mathrm{C}$ temperature, humidity $50 \pm 5 \%, 12 \mathrm{~h}$ cycle dark/light.

PLGA nanoparticles loaded with vitamin E were provided by the Department of Biological and Agricultural Engineering, Louisiana State University, 70803, Louisiana, United States as a donation. The PLGA-NPs were spherical in shape, measured $95 \pm 2 \mathrm{~nm}$, had a negative zeta potential $(-38 \mathrm{mV})$ and the polydispersity index (PDI) was 0.12 . The synthesis of these NPs was described in detail by the inventors who got a patent for them [11]. A briefly description of the morphology, of the tissue tropism and toxicity for PLGA-NPs loaded with vitamin E, was also done by some of our coauthors [12].

Before being sacrificed the animals were fasted for $12 \mathrm{~h}$ and sedated with Ketamine $(25 \mathrm{mg} / \mathrm{kg}$ weight) and then weighed. Blood samples and the kidneys were collected and measured from each animal.

\subsection{Biochemical analysis}

Blood samples were centrifuged at $3000 \mathrm{rpm}$ for $5 \mathrm{~min}$ and the serum was used for metabolic parameters detection. Kits had been provided from Biosystems (Spain). From kidney homogenates, MDA was detected using the spectrophotometry method with thiobarbituric acid on the biochemistry analyzer Cecil 1000 [13]. The kidney total thiols content were measured following the Beutler E et al method by using the colour reactant 5,5'-dithiobis-(2-nitrobenzoic acid) (DTNB, Sigma Chemical Co.) The absorbance was read at $412 \mathrm{~nm}$ [14].

Kidney samples were fixed in buffered $10 \%$ formaldehyde for $24 \mathrm{~h}$. The samples were automatically processed with tissue processor STP 120-3 (Thermo Fischer Scientific, USA) and paraffin embedding was done with modular tissue Microm EC 350-1 (Thermo Fischer Scientific, USA). The resulting blocks were cut at $3 \mu \mathrm{m}$ using the RM 125RTS (Leica, Germany) microtome. The sections were stained with hematoxylin and eosin. The examination was performed with an Olympus BX43 microscope (Olympus, Japan) coupled to an Olympus DP73 (Olympus, Japan) video camera 
and using the Olympus Cell^B analysis system (Olympus, Japan) for microscopic evaluation of the samples.

\subsection{Statistical analysis}

It was performed using a Student's t-test (two tailed, unpaired) to compare and correlate biochemical biomarkers with clinical parameters and anatomo-pathological parameters. Mean \pm standard deviation (SD) values were calculated. Statistical significance was set at a p-value of <0.05.

The Ethics Committee of Scientific Research of 'Carol Davila' University of Medicine and Pharmacy, Bucharest, Romania approved the experimental protocol. The experiment was performed, at the University Biobase. Regarding the protection of animals used for experimental and other scientific purposes, the EU Directive 2010/63 approved in 2014 was observed.

\section{Results and discussions}

The serum biological results, the renal MDA, the total renal thiols values and the renal histopathologic aspects are shown in the following table and figures.

Table 1. Comparison of the average values of serum parameters for the studied groups

\begin{tabular}{|c|c|c|c|c|}
\hline \multirow{2}{*}{ Parameters } & \multicolumn{2}{|c|}{ Obesogenic diet groups } & \multicolumn{2}{c|}{ Standard diet groups } \\
\cline { 2 - 5 } & O group & ON group & S group & \multicolumn{2}{c|}{ SN group } \\
\hline FBG (mg/dL) & $140 \pm 0.084^{\mathrm{a}^{*}}$ & $1.58 \pm 0.143$ & $1.355 \pm 0.092$ & $117 \pm 10.39$ \\
\hline Triglyceride (mg/dL) & $172.66 \pm 10.313^{\mathrm{a}^{*}}$ & $126 \pm 6.35^{\mathrm{b}^{*}}$ & $120.5 \pm 6.363$ & $58 \pm 8.71^{\mathrm{c}^{*}}$ \\
\hline Total protein (g/dL) & $5.55 \pm 0.35$ & $156.66 \pm 23.7$ & $5.8 \pm 0.141$ & $5.66 \pm 0.26$ \\
\hline ALT (UI/L) & $73 \pm 2.82$ & $81 \pm 10.39$ & $71 \pm 2.82$ & $83.33 \pm 10.1$ \\
\hline Cholesterol (mg/dL) & $65.33 \pm 4.93$ & $42 \pm 7.07$ & $66.5 \pm 10.6$ & $58.66 \pm 10.6$ \\
\hline Cystatin (mg/dL) & $0.18 \pm 0.035^{\mathrm{a}^{*}}$ & $0.17 \pm 0.04$ & $0.13 \pm 0$ & $0.14 \pm 0.01$ \\
\hline Creatinine (mg/dL) & $0.58 \pm 0.14^{\mathrm{a}^{*}}$ & $0.51 \pm 0.02^{\mathrm{b}^{*}}$ & $0.52 \pm 0.02$ & $0.48 \pm 0.05^{\mathrm{5}^{*}}$ \\
\hline Urea (mg/dL) & $38 \pm 1.14^{\mathrm{a}^{*}}$ & $34 \pm 2.72$ & $32 \pm 2.72$ & $35.5 \pm 2.29$ \\
\hline
\end{tabular}

FBG=fasting blood glucose; $\mathrm{a}^{*}$ : $\mathrm{p}<0.02$ between $\mathrm{O}$ and $\mathrm{S}$ groups; $\mathrm{b}^{*}: \mathrm{p}<0.05$ between $\mathrm{O}$ and $\mathrm{ON}$ groups; $\mathrm{c}^{*}$ : $\mathrm{p}<0.05$ between $\mathrm{S}$ and $\mathrm{SN}$ groups

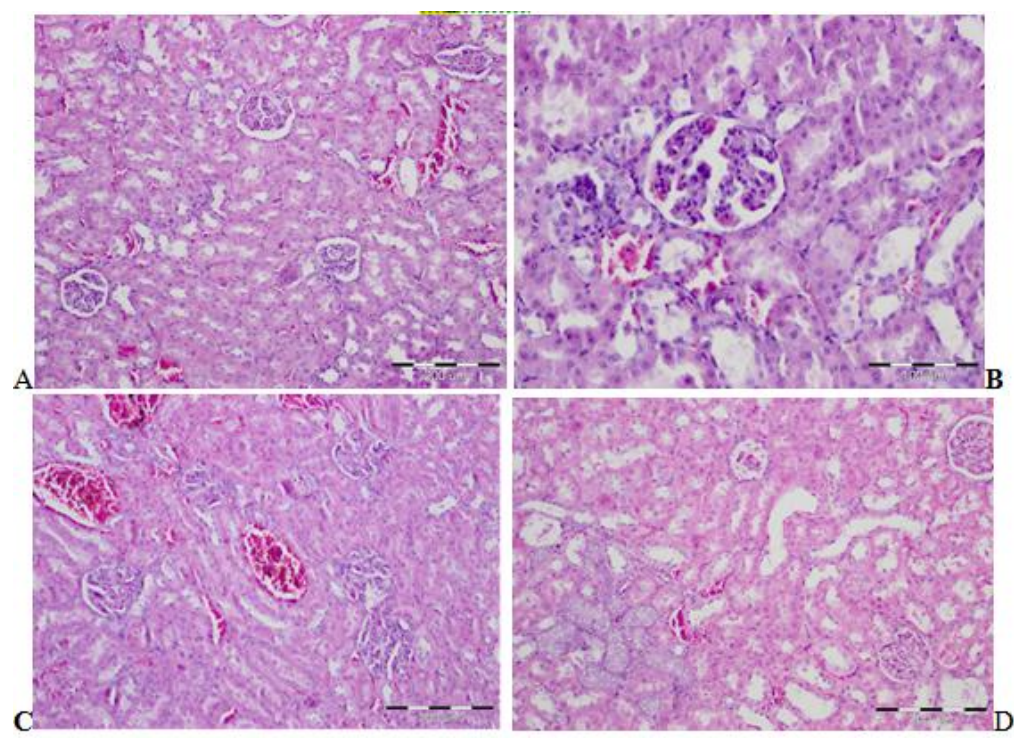

Figure 1. The histopathological aspect of kidney. Hematoxylin-eosin stain, for:

O group (A), ON group (B), S group (C) and SN group (D). A. GroupO (obx10) - the glomerular capillaries and interstitial vessels showed moderate congestion and occasional periglomerular mononuclear inflammatory infiltrate and tubulonephrosis; B. Group ON (obx20) - glomerular

capillaries hyperemia with minimal inflammatory infiltrate; C. Group S (obx10) - isolated periglomerular minimal mononuclear inflammatory infiltrate and tubulonephrosis; D. Group SN (obx10) - moderate tubulonephrosis and interstitial and glomerular hyperemia without inflammation 
Obesity is a preventable risk factor for chronic kidney disease. It has been demonstrated that obesity related glomerulophathy increased 10-fold in recent years. The increased body weight is associated with raised metabolic demands and a compensatory hyperfiltration mechanism occurs. As a concequence, the increased intraglomerular pressure can affect the kidneys. In long term, the process can expand and enhance the risk of end-stage renal disease [15].

The increased reabsorption of sodium from Henle's loop and altered pressure natriuresis are due to the renin-angiotensin-aldosterone system activation, to sympathetic nervous system hyperactivity and to the compressive effect of the kidney loaded with intrarenal fat [16].

In this study, the renal function markers: urea, cystatin and creatinine were in the normal range, but significantly higher in the obese group versus normal weight Wistar rats (Table 1). Each time when the treatment was associated to the two types of the diet, creatinine values were improved (Table 1).

Data literature showed that there is an association between kidney function markers and dyslipidemia. In our study, dyslipidemia with high triglycerides was induced by the high caloric/high fat diet in the young Wistar rats (Table 1). The group $\mathrm{O}$ had the highest levels both for triglycerides and for the renal function markers: cystatin, urea and creatinine (Table 1). In animal and human studies, it has been demonstrated that triglyceride plasma level is an independent risk factor for the progression of renal disease [17].

There is a dual link between dyslipidemia and chronic kidney disease. Dyslipidemia is a common complication of progressive kidney disease and on the other hand, it is involved in the development and progression of renal disease [18].

Tozawa et al. demostrated that triglycerides, but not cholesterol or low density lipoprotein cholesterol levels predicted a risk of developing proteinuria in the following three years [19]. In another study it was demonstrated that in hypercholesterolemic male rats, testosterone eliminates the attenuating effect of castration on the progressive glomerular injury [20].

In our study, vitamin $\mathrm{E}$ loaded nanoparticles treatment decreased triglyceridemia, but cholesterolemia, proteinemia and glycaemia were similar between the treated and the untreated groups (Table 1).

In the early stages of obesity, glomerular hyperfiltration and increased arterial blood pressure help to offset the increased tubular reabsorption process. However, all these changes will lead to capillary wall stress, chemotactic proinflammatory effects with increased glomerular proliferation and matrix accumulation, and ultimately glomerulosclerosis changes, with subsequent loss of nephron function $[15,16]$. In our study, the young high weight Wistar rats were able to maintain the serum cystatin and creatinine within normal range (Table 1), at the upper limit, but the kidney histopathologic modifications developed early (Figure 1).

By comparing the histopathologic aspects (Figure 1) of the $\mathrm{O}$ group with $\mathrm{S}$ group, we can observe that obesogenic diet produced tissue injuries: periglomerular inflammatory cells versus occasional periglomerular inflammation, severe tubulonephrosis and ectasiated blood vessels in the stroma versus simple tubulonephosis.

By comparing the histopathologic kidney aspects of the $\mathrm{O}$ group with $\mathrm{ON}$ group, and S group with SN group we can observe that vitamin E loaded nanoparticles treatment reduced the inflammatory process and maintained the integrity of the renal filtration space (Figure1).

A clinical study made on 60 patients with diabetic nephropathy evaluated the effect of vitamin $\mathrm{E}$ versus placebo supplementation on biomarkers of renal injury, renal inflammation and of oxidative stress, over a 12-week period. The results showed a significant increase of vitamin E serum level, decreased proteinuria, decreased ratio proteinuria/creatinine, decreased serum TNF- $\alpha$, matrix proteinases 2, 9 and MDA [21]. Also, in an experimental study, a reduced liver MDA concentration was demonstrated by maternal use of Nigella sativa oil rich in vitamin E during pregnancy and lactation period [22]. On the other hand, the beneficial effects observed in Wistar rats with non alcoholic fatty liver disease treated with one high dose of vitamin E PLGA-NPs represent an argument 
that this type of treatment is an attractive and promising alternative for chronic liver disease management [23].

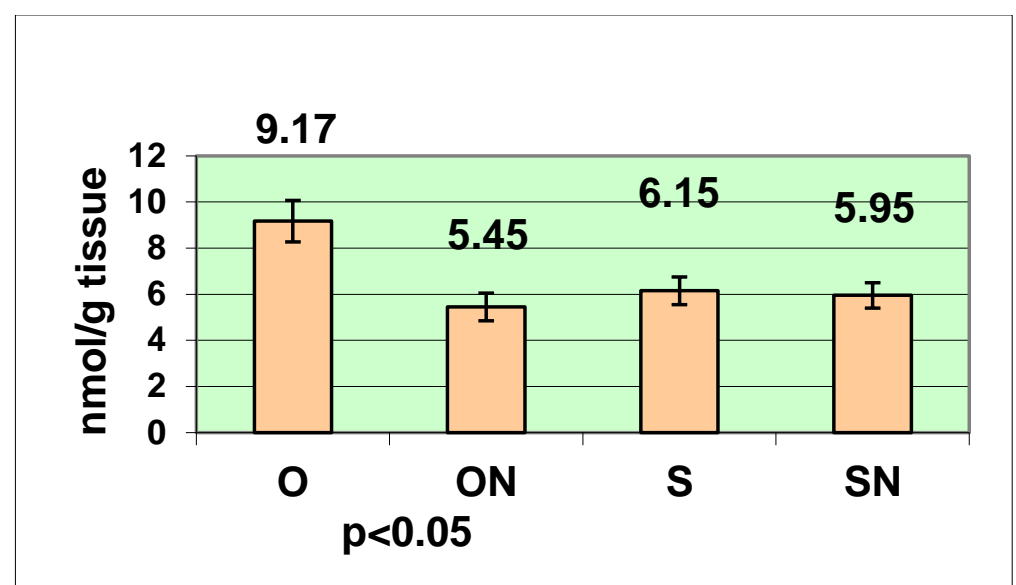

Figure 2. Kidney malondialdehyde (MDA); the only significant $\mathrm{p}$ value $(\mathrm{p}<0.05)$ was between $\mathrm{O}$ and $\mathrm{ON}$ group

The histopathologic results of the present study are in agreement with the kidney homogenates oxidative stress values (Figures 1, 2, 3).

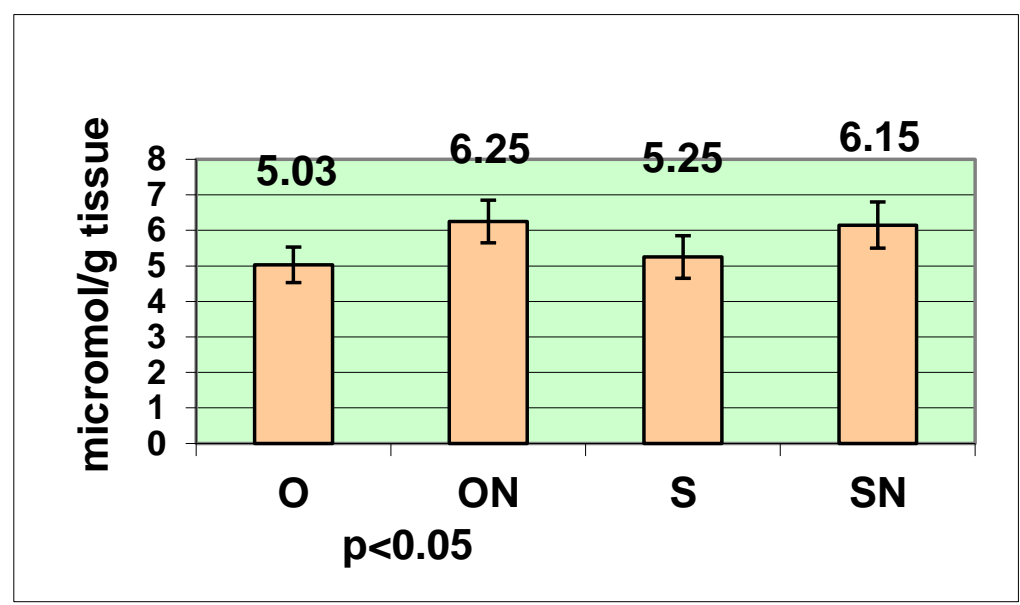

Figure 3. Kidney total thiols, the only significant $\mathrm{p}$ value $(\mathrm{p}<0.05)$ was between $\mathrm{O}$ and $\mathrm{ON}$ group

The histopathologic results of the present study are in agreement with the kidney homogenates oxidative stress values (Figures 1,2,3). The reduced level of renal total thiols and the increased level of MDA may have contributed to periglomerular mononuclear inflammatory infiltrate and tubulonephrosis. The association of PLGA-NPs loaded with vitamin E to the obesogenic diet reduced the increased MDA (68.25\%) and increased the reduced total thiols values (23\%). By decreasing the lipid peroxidation in the kidney and by increasing the antioxidant defence, the treatment provided protection against degenerative changes in the kidney.

It was demonstrated that disproportionally lower muscle mass in relation to increased metabolically active visceral fat mass is associated with poor outcome in the end stage renal disease [24].

In our study, the Wistar rats fed with obesogenic diet for 7 weeks had higher values for the ratio kidney weight/body weight (Figure 4$)$ than the ones on standard diet $(\mathrm{p}<0.05)$. Hegenar et al. had also demonstrated higher kidney weights in dogs fed with high fat diet [25]. The treatment didn't influence the kidneys weight. 


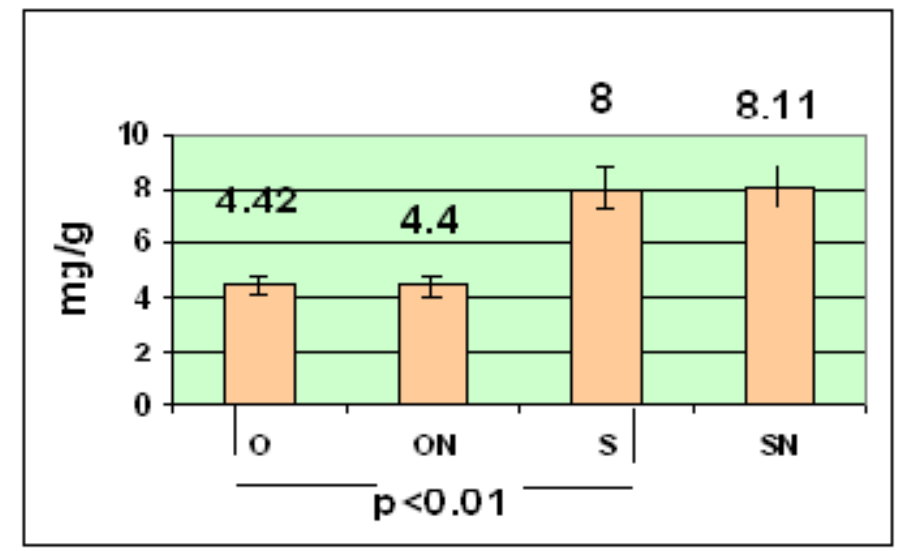

Figure 4. The ratio kidney weight/ body weight $(\mathrm{mg} / \mathrm{g})$; the only significant $p$ value, $(p<0.01)$ was between $\mathrm{O}$ and $\mathrm{S}$ group

Overweight and obese persons have at least 3 fold increased risk of developing chronic kidney disease in comparison to normal weight subjects [26]. Weight loss improves glomerular filtration rate, decreases proteinuria and maintains podocyte function $[27,28]$.

Our investigation presents some points that should be addressed. We did not include in this study the group of rats treated with "classic" vitamin E drug. Considering the results of Trauber's MG research team that "Obesity-associated hepatosteatosis may produce unrecognized hepatic vitamin $\mathrm{E}$ sequestration" or"... tissues of obese people are rejecting intake of some of lipids, including vitamin E" we have elaborated the study, using one of best delivery system of vitamin E to the kidney, the PLGA-NPs loaded with this vitamin. Also, the renal oxidative stress markers measured, the MDA and total thiols are old ones, with low sensitivity and specificity. Nevertheless, we tried to corroborate the renal balance, MDA/total thiols with kidney histopathologic aspects and blood kidney function parameters (creatinine, cystatin). The extrapolation of the results from Wistar rats to humans represents another challenge for researchers.

Polylactic-co-glycolic acid nanoparticles (PLGA-NPs) charged with Vitamin E may demonstrate promising results in decreasing side effects of hypercaloric/hyperlipidic diet. Recently, our team presented as a poster, a comparative effect of oral vitamin E drug versus PLGA-NPs charged with vitamin $\mathrm{E}$ on visceral rat fat [31]. Nanoformulation has demonstrated remarkably higher systemic bioavailability in tissues and reduced more the visceral fat compared to free drug administration [31].Intervention with PLGA-NPs loaded with vitamin E should be confirmed in human clinical trials and may be a good alternative method for the prevention of visceral fat comorbidities.

\section{Conclusions}

The obesogenic diet, for 7 weeks, in young Wistar male rats produced kidney injuries. The biological markers of kidney function, the renal oxidative stress status and the histopathologic kidney aspects were unisonly modified, showing the onset of renal damage. The group that received vitamin $\mathrm{E}$ loaded nanoparticles was protected, having lower degenerative kidney modifications, lower lipid peroxidation level and also a decreased inflammatory process. The improvement of the histopathologic aspect is a strong argument that administration of PLGA-NPs loaded with vitamin $\mathrm{E}$ in high fat diet Wistar rats has a preventive effect in degenerative injuries. 


\section{References}

1.FINKELSTEIN, E.A., STROMBOTNE, K.L., POPKIN, B.M., Choices, 3rd Quarter, 25(3), 2010, p.1.

2.RHEE CM, AHMADI SF, KALANTAR-ZADEH K., Curr Opin Nephrol Hypertens. 25(3), 2016, p.208. doi:10.1097/MNH.0000000000000212.

3.ASTETE, C.E., SABLIOV, C.M., Journal of Biomaterials Science Polymer Edition, 17(3), 2006, p. 247.

4.MAKADIA, H.K., SIEGEL, S.J., Polymers, 3, 2011, p.1377.

5.SIMON LC, SABLIOV CM, Drug Metab Rev, 2014 May5;46(2):128-41.

6.FENG, Y., Biomed Mater Eng., 26 Suppl 1, 2015, p.S2133.

7.MURRAY, M., Encyclopedia of Nutritional Supplements: The Essential Guide for Improving Your Health Naturally, Harmony, ISBN 0761504109 (ISBN13: 9780761504108), 1996

8.LAURENTIUS, T., RAFFETSEDER, U., FELLNER, C., KOB, R., NOURBAKHSH, M., FLOEGE, J., BERTSCH, T., BOLLHEIMER, L.C., OSTENDORF, T., J Inflamm (Lond). 2019; 16: 14. Published online 2019 Jun 25. doi: 10.1186/s12950-019-0219-x.

9.ZHAO, Y., ZHANG, W., JIA, Q., FENG, Z., GUO, J., HAN, X., LIU, Y., SHANG, H., WANG, Y., LIU, W.J., Front Physiol. 2018; 9: 1939. Published online 2019 Jan 21. doi: 10.3389/fphys. 2018.01939.

10.BUCIOLI, S.A., de ABREU, L.C., VALENTI, V.E., LEONE, C., VANNUCCHI, H., BMC Complement Altern Med. 2011; 11: 133. Published online 2011 Dec 20. doi: 10.1186/1472-6882-11133.

11.ZIGONEANU, I.G., ASTETE, C.E., SABLIOV, C.M., Nanotechnology, 2008, 19(10): 105606105701 .

12.MIRICESCU, D., STANESCU, I., PERLEA, P., CALENIC, B., RADULESCU, R., TOTAN, A., VIRGOLICI, B., SABLIOV, C., GREABU, M., Materiale Plastice, 2017, 5, No.2, 249-252.

13.ESTERBAUER, H., CHEESEMAN, K.H., Methods in enzymology. Vol. 186: Oxygen radicals in biological systems. Part B: Oxygen radicals and antioxidants, Elsevier, Packer L., Glazer A.N. (eds), 1990, p.407- 42.

14.BEUTLER, E., DURON, O., KELLY, B.M., J Lab Clin Med, 1963, 61, p.882-888

15.KOVESDY, C.P., FURTH, S.L., ZOCCALI, C., Indian J. Nephrol., Mar-Apr; 27(2), 2017, p.85.

16.HALL, J.E., BRANDS, M.W., HENEGAR, J.R., Ann N Y Acad Sci. Nov 18; 892, 1999, p.91.

17.TREVISAN, R., DODESINI, A.R., LEPORE, G., JASN 17 (4 suppl 2), April 2006, p.S145; DOI: https://doi.org/10.1681/ASN.2005121320

18.CASES, A., COLL, E., Kidney International, Volume 68, Supplement 99, December 2005, p. S87

19.TOZAWA M, TAKISHITA, S., Kidney International vol 62 November 2002, p. 1743.

20.SAKEMI T, TOYOSHIMA H, MORITO F., Nephron. 67(4), 1994, p.469. Epub 1994/01/01. pmid:7969682.

21.KHATAMI, P.G., SOLEIMANI, A., J Clin Lipidol.;10(4), 2016 Jul-Aug, p.922.

22.CONSTANTINESCU, M.Z., VIRGOLICI, B., STEFAN, D.C.A., MIRICESCU, D., LIXANDRU, D., POPESCU, L., VIRGOLICI, H., GUBCEAC, E., MOHORA, M., REV.CHIM.(Bucharest), 67, No. 11,2016, p.2435.

23.TOTAN, A., BALAN, D.G., MIRICESCU, D., RADULESCU, R., STANESCU, I.O., VIRGOLICI, B., MOHORA, M., GREABU, M., REV.CHIM., 70, No. 1, 2019, p.78.

24.STENVINKEL, P., ZOCCALI, C., IKIZLER, T.A., J. Am. Soc. Nephrol.,24, 2013, p.1727

25.HENEGAR, J.R., BIGLER, S.A., HENEGAR, L.K., TYAGI, S.C., HALL, J.E., J.Am.Soc.Nephrol.;12(6), 2001 Jun, p.1211.

26.EJERBLAD, E., FORED, C.M., JASN, vol. 17, no. 61695, June 2006, p.1702.

27.WICKMAN, C., KRAMER, H., Semin.Nephrol., 33(1), 2013 Jan, p.14.

28.KONG, L., WU, H., ZHOU, W., LUO, M., TAN, Y., MIAO, L., CAI, L., Mol Med., 21(1), 2015, p.87; doi: 10.2119/molmed.2014.00211. 
29.VIOLET, P.-C. EBENUWA, I.C., WANG, Y., NIYYATI, M., PADAYATTY, S.J., HEAD, B., WILKINS, K., CHUNG, S., THAKUR, V., ULATOWSKI, L., ATKINSON, J., GHELFI, M., SMITH, S., TU, H., BOBE, G., LIU, C.-Y., HERION, D.W., SHAMBUREK, R.D., MANOR, D., TRABER, M.G., LEVINE, M., JCI Insight. 2020;5(1):e133309.

30.***https://lpi.oregonstate.edu/feature-story/obese-people-need-more-vitamin-e-actually-get-less https://doi.org/10.1172/jci.insight.133309.

31.DINU, A., DINU, G.A., BALABAN, M., VIRGOLICI, B., MIRICESCU, D., TOTAN, A., GREABU, M., MOHORA, M., Revista Română de Medicină de Laborator, Supliment 1 la Vol. 27, Nr. 2, Aprilie, 2019 poster Romanian Journal of Laboratory Medicine

$\overline{\text { Manuscript received: } 25.02 .2020}$ 